\title{
Competência em comunicação e cultura de inovação nas organizações: breves reflexões
}

COMPETENCE IN COMMUNICATION AND INNOVATION CULTURE IN ORGANIZATIONS: BRIEF REFLECTIONS

\section{Maria Eugênia Porém}

Professora da Universidade Estadual Paulista (Unesp). Doutora em Educação e Mestre em Comunicação pela Unesp.

E-mail: meporem@faac.unesp.br

\section{Tamara de Souza Brandão Guaraldo}

Professora da Universidade Estadual Paulista (Unesp). Doutora em Ciência da Informação, Mestre e Bacharel em Comunicação pela Unesp.

E-mail: tamara@faac.unesp.br

\section{Raquel Cabral}

Professora da Universidade Estadual Paulista (Unesp). Doutora em Comunicação/Universitat Jaume I (Espanha), Mestre e Bacharel em Comunicação pela Unesp.

E-mail: raquelc@faac.unesp.br

\section{Roseane Andrelo}

Professora da Universidade Estadual Paulista (Unesp). Doutora em Educação e Mestre em Comunicação pela Unesp.

E-mail: roseane.andrelo@faac.unesp.br

Recebido em 20 de julho de 2015. Aprovado em 18 de novembro de 2015.

\section{Resumo}

Reflexões acerca da comunicação como competência essencial de uma organização para a promoção da cultura de inovação. Parte-se do pressuposto de que a forma como a comunicação se relaciona e colabora na constituição de uma organização compõe um forte elemento indutor do processo de inovação no âmbito organizacional. Trata-se do reconhecimento da comunicação como uma competência essencial, que pressupõe a hibridização da competência em comunicação com a cultura de inovação. Para tanto, a pesquisa teórica será empregada com fins exploratórios e conceituais. 
Palavras-chave: Comunicação. Competência em comunicação. Cultura de inovação.

\section{Abstract \\ Reflections on communication as a core com- petence of organizations for the promotion of innovation culture. It presumesthat the way the communication relates and assists in setting up an organization composes a strong inducing element}

in the innovation process in the organizational context. It is the recognition of communication as a core competence which deals with the hybridization of the communicative competence of the organization with the innovation culture. In order to do so, it is applied a theoretical research with exploratory and conceptual purposes.

Keywords: Communication. Communication competence. Innovation Culture.

\section{Introdução}

O texto busca refletir sobre como a comunicação se relaciona e colabora na promoção da cultura de inovação em uma organização, constituindo-se em um forte elemento indutor do processo de inovação no âmbito organizacional. Tem como objetivo discutir o reconhecimento da comunicação como uma competência essencial à cultura de inovação, e, além de propor reflexões iniciais sobre a temática, tenta estabelecer uma relação conceitual entre competências essenciais, competência em comunicação e cultura de inovação no âmbito das organizações.

A metodologia, de caráter exploratório, compreende o uso de pesquisa bibliográfica que envolve síntese e diálogo com as fontes utilizadas. É um processo de escrita própria em que se privilegia a reflexão que surge do contato com as fontes e do confronto com a observação da realidade (DMITRUK, 2004). Além de discutir a relação entre competência em comunicação e cultura de inovação, a pesquisa teórica também permite conhecer a perspectiva de que a comunicação não se limita a um caráter instrumental, o que tende a diminuir sua importância e protagonismo na realidade organizacional, pois essa se constitui em competência essencial num cenário marcado pela competitividade e vulnerabilidade das organizações.

\section{Relação conceitual: competências essenciais, competência em comunicação e cultura de inovação}

Baseada em relações que se estabelecem mediadas pela informação e comunicação e na geração do conhecimento, a sociedade em rede (CASTELLS, 1999) representa um novo momento histórico em que a cultura digital, ou cibercultura (LEVY, 1999), 
estabelece espaços interacionais por meio da internet, da informática e da convergência midiática (JENKINS, 2009). São novos valores sendo introduzidos em ambientes virtualizados e digitalizados, transformando o modus operandi da sociedade e de suas organizações.

Nesse cenário, criam-se outras experiências humanas e sociais em relação espaço-tempo (rede), permitindo a formação de uma inteligência coletiva, facilitada pelo acesso à internet e por ambientes virtuais de trocas colaborativas e participativas.

Especialmente nas organizações, novas posturas e procedimentos são percebidos como necessários à mudança diante dos desafios marcados duramente pela competitividade, internacionalização e um novo modelo de mercado consumidor.

Diante dessa realidade, organizações buscam flexibilizar estratégias que sejam capazes de impulsionar os negócios e a economia a fim de atender a um novo consumidor - mais exigente, mais atento, mais informado e virtualizado -, para ampliar a atuação local e global e, certamente, aumentar a sua competitividade.

A competitividade depende da capacidade de adequação das organizações às oscilações e vulnerabilidades do ambiente no qual estão inseridas. É certo afirmar que a busca por estratégias que viabilizem essa adequação e proporcionem vantagem competitiva perpassa pela capacidade de geração, absorção e introdução de inovações.

Por essas e outras razões, a inovação passou a fazer parte da agenda de diferentes setores da sociedade, se tornando protagonista das estratégias das organizações, tanto em nível nacional quanto internacional.

O fato é que a inovação pode ser vista como catalisadora do desenvolvimento econômico e social, capaz de gerar maior competitividade e, ainda, tem relação direta com a geração de emprego e renda, fatores que promovem a economia nacional e o progresso técnico e tecnológico de um país.

Chesbrough (2006) destaca que uma organização que tem habilidade em inovação pode ter mais chance de sobreviver e ter sucesso em um mercado competitivo e turbulento.

Não obstante, a inovação para uma organização pode resultar em melhorias e mudanças, uma vez que pressupõe um estado contínuo de geração e disseminação de conhecimento. Dessa forma, causa impacto no seu desenvolvimento e esse, consequentemente, muda sobremaneira uma situação anterior, transformando comportamentos e visões, processos e pessoas.

A palavra inovação é derivada do termo latino innovatio e se refere a uma ideia, método ou objeto que é criado e que pouco se parece com padrões anteriores. Para Freeman (1982), inovação é o processo que inclui as atividades técnicas, concepção, desenvolvimento, gestão e que resulta na comercialização de novos (ou melhorados) produtos ou na 
primeira utilização de novos (ou melhorados) processos. Segundo Schumpeter (1982), o motor que move o desenvolvimento do capitalismo é a inovação. E, embora não se tenha um consenso em torno do conceito de inovação, em linhas gerais, podemos relacionar a inovação à introdução de uma novidade ou renovação em qualquer atividade, seja ela humana, empresarial, mercadológica e/ou produtiva.

No Manual de Oslo (OECD, 2005), inovação se refere à melhoria ou implementação de novos produtos ou serviços, processos, métodos de marketing ou métodos organizacionais. Segundo Zmoginski et al (2009, p. 49), o Manual de Oslo (OCDE, 2005) conceitua quatro tipos inovação: "de produto, de processo, de marketing e organizacionais - ou no modelo de negócio".

Mais do que um conceito, convém ponderar que inovar não é uma atividade simples. Ela requer muito mais que boa vontade, disponibilidade financeira ou um perfil empreendedor e arrojado de uma organização.

Segundo Moura e Krumholz (2010), inovação está ligada à mudança, quer incremental, radical ou revolucionária - em conceitos, produtos, processos ou organizações. E, complementam as autoras: "a capacidade de inovar cria o tipo de mudança que ao mesmo tempo permite a organização adaptar-se ao mundo que está ao seu redor, e também influencia este mundo a adaptar-se" (MOURA; KRUMHOLZ, 2010, p. 6).

Mudança organizacional é sensível e inexorável à inovação, fato que justifica relacionar inovação à cultura da organização, na medida em que pela cultura se formam os valores e os pressupostos que identificam uma organização.

Não por acaso, Steele e Murray (2004, p. 321) afirmam que "a agilidade e habilidade de uma organização responder às mudanças do mercado recai no capital intelectual das pessoas". Logo, a "cultura afeta inovação porque molda os padrões de lidar com a novidade, iniciativas individuais e ações coletivas e entendimentos e comportamentos em termos de riscos assim como de oportunidades" (KAASA; VADI, 2010, p. 584).

Uma organização inovadora possui determinadas características culturais que a fazem como tal. Dentre elas destacam-se, segundo Knox (2002), os comportamentos, atitudes e capacidades das pessoas que trabalham na organização. Essas, por sua vez, devem ser direcionadas por uma cultura organizacional que encoraje o intraempreendedorismo, a geração de ideias e a criatividade, a comunicação fluída e transparente, o diálogo e o emponderamento.

Dobni (2008) afirma que a cultura organizacional é um dos fatores que influenciam os processos de inovação nas organizações. Dessa forma, faz parte de uma cultura organizacional que estimule a inovação à adoção de um modelo de gestão cujo alicerce fundamenta-se na liberdade de expressão, no engajamento, na co-participação dos agentes organizacionais. Assim, para Ahmed (1998), a cultura é a base da inovação, constituindo-se 
como um dos fatores que facilitam e impulsionam a inovação ou, ao contrário, criam barreiras impeditivas.

Partindo desse princípio, a inovação deve estar relacionada ao modelo de gestão assumido por uma organização e introjetado em sua cultura organizacional. Queremos dizer que a inovação deve ser internalizada pelos agentes dessa organização como propósito e transformada em conduta empresarial, aderente à rotina organizacional, em um continuum. "Neste continuum, a cultura corporativa de inovação é criada pelo que as pessoas dizem, como se comunicam, como tratam umas às outras e aos seus clientes, como inovam, e como e por que os dirigentes tomam suas decisões, dentre outros fatores" (MOURA; KRUMHOLZ, 2010, p. 2).

Não por acaso relaciona-se a cultura organizacional à inovação. Isso porque torna-se inevitável que os sentidos e os valores de uma organização, ou seja, sua cultura, projetem o compartilhamento coletivo de postura inovativa de seus agentes.

Segundo Jaskyte e Dressler (2004, p. 274), cultura organizacional pode ser vista como "um conjunto de valores compartilhados que auxiliam os membros da organização a compreender o funcionamento organizacional e assim guiar o pensamento e comportamento". Logo, a cultura organizacional pode ser facilitadora ou inibidora da inovação.

Bruno-Faria e Fonseca (2004), em seus estudos sobre a relação entre cultura organizacional e inovação, citam, por exemplo, McLean (2005, p. 241), que afirma que "a cultura cria os parâmetros para qual comportamento é desejável e será encorajado e qual comportamento é inaceitável e será censurado".

Em uma pesquisa sobre organizações inovadoras, Zien, citado por Stevens (1998), identificou algumas características comuns a elas e que podemos relacionar à cultura organizacional, que são expostas no quadro 1:

Quadro 1. Algumas características comuns a organizações inovadoras

\begin{tabular}{|c|l|}
\hline Característica & $\begin{array}{l}\text { Todos, sem exceção, sentem-se comprometidos com o processo de inovação. } \\
\text { Não existe um grupo específico encarregado de zelar pela criatividade. }\end{array}$ \\
\hline Estimulada & $\begin{array}{l}\text { O clima de inovação é instaurado pelo dirigente da empresa, embora ele } \\
\text { não seja necessariamente um inventor. Toda ideia nova é bem-vinda e a } \\
\text { criatividade e a ousadia são recompensadas. }\end{array}$ \\
\hline Ilimitada & Os experimentos estão por toda parte. Não se restringem à área tecnológica. \\
\hline Cultuada & $\begin{array}{l}\text { As conversas nas empresas inovadoras são pródigas em histórias e lendas de } \\
\text { pessoas que introduziram novidades, às vezes até quebrando regras. }\end{array}$ \\
\hline Interativa & $\begin{array}{l}\text { Existem vários canais de comunicação abertos para garantir uma autêntica } \\
\text { interação entre a direção e os funcionários, os técnicos e os vendedores, } \\
\text { a empresa e os clientes. Essas ricas e profusas redes não são rigidamente } \\
\text { controladas. }\end{array}$ \\
\hline
\end{tabular}

Fonte: Adaptado de Stevens (1998) 
Nessa perspectiva, é possível reconhecer que organizações inovadoras possuem determinantes em sua cultura organizacional que delineiam a sua gestão e que são capazes de incentivar ou não essa inovação.

Cabe salientar o aspecto $5^{\circ}$ do quadro 1 , pois identifica que a interatividade é uma das características comuns às organizações inovadoras. E, muito embora sua descrição se limite a caracterizar instrumentalmente a comunicação, podemos afirmar que ela perpassa todas as outras características, na medida em que cada uma delas se legitima por meio da comunicação/interação. Isso porque são os agentes organizacionais que interagem para constuituir uma organização por meio da sua cultura. Queremos dizer que uma organização é uma realidade socialmente construída (BERGER; LUCKMANN, 2003) pelos seus agentes, que ao interagirem entre si, com o ambiente organizacional, com seus valores e identidades e com outras culturas, dão significado à própria cultura organizacional.

Parte-se do pressuposto que uma organização, para se tornar inovadora, necessita desenvolver a cultura de inovação, uma vez que segundo Ahmed (1998), inovar é a força motriz da transformação e a cultura é seu principal determinante.

Para Kuczmarski (1998 apud BRUNO-FARIA; FONSECA, 2014), “o segredo das organizações inovadoras está em criar uma consciência inovadora, ou seja, internalizar a cultura da inovação".

Moura e Krumholz (2010) se referem ao desenvolvimento de um ecossistema de inovação em que a cultura é o fundamento que alimenta todas as relações sinérgicas que o formam. As mesmas autoras, ao citarem Angel (2006 apud MOURA; KRUMHOLZ, 2010), ainda argumentam que a cultura de inovação é representada em forma de "um continuum que evolui do nível básico para os níveis avançado e disruptivo ou radical".

Podemos definir cultura de inovação como:

[...] um contexto multidimensional que inclui a intenção de ser inovativo, a infraestrutura que dá suporte à inovação, comportamento de nível operacional necessários a influenciar o mercado e a orientação de valor e o ambiente para implementar a inovação (DOBNI, 2008, p. 540).

Dessa forma, a cultura de inovação envolve fatores estruturais, internos, externos e até pessoais, na medida em que deve ser uma postura incorporada pelos agentes de uma organização.

Por isso, organizações inovam de maneira diferente umas das outras. Pois são as pessoas desta organização seus agentes inovativos; entram em jogo as suas subjetividades, culturas e subculturas, modelos mentais, histórias de vida e experiências particulares 
que, em articulação com a realidade organizacional e com a cultura organizacional, ressignificam suas posturas e comportamentos.

Dessa forma, corroboramos com Prego (2014, p.32) ao afirmar que "cada organización necesita encontrar su propia y única forma de innovar, basándose en el conocimiento, pero adaptándolo a las particularidades de las personas".

Melhor dizendo, uma organização inovadora depende da forma como os agentes organizacionais - funcionários, gerentes, corpo diretivo etc - assimilam e incorporam a cultura de inovação, da sua valorização e de o quanto eles estão dispostos a fazer em prol da difusão e disseminação da inovação por meio de processos comunicativos que sejam capazes de legitimá-la.

Logo fica evidente a comunicação como mola propulsora da cultura de inovação, uma vez que "ela é o oxigênio que confere vida às organizações. Está presente em todos os setores, em todas as relações, em todos os fluxos de informação, espaços de interação e diálogo" (DUARTE; MONTEIRO, 2009, p. 334).

Duarte e Monteiro (2009) chamam atenção para uma questão importante: apesar da relevância da comunicação e de que a mesma pode gerar mais valor para uma organização, vivencia-se ainda um paradoxo ao não conseguir transformar essa força motriz em energia vital. Em outras palavras, existem barreiras organizacionais que impedem que a comunicação se transforme em competência essencial da organização.

A consequência desse quadro interfere, dentre outras coisas, na promoção da cultura da inovação, na medida em que "da comunicação emergem as culturas em uma organização. A comunicação cria e recria realidades” (MARCHIORI, 2008, p.192). Pois, parte-se da abordagem de que a comunicação é definida pela interação de pessoas nas e entre organizações e é entendida como um processo constitutivo da realidade organizacional (CALDAS, 2010). Partimos de análises subjetivas e interpretativas da realidade organizacional, ultrapassando a visão mecanicista de comunicação que a coisifica "como mais um elemento instrumental à disposição do gestor em busca da performance organizacional" (CALDAS, 2010, p. 34-35).

Se assim o é, organizações cuja comunicação é considerada competência para a construção da realidade organizacional tenderiam a ter maior facilidade para inovar, na medida em que a incorporação da cultura de inovação é facilitada pelos processos comunicativos fundamentados por uma rede de representações complexas e subjetivas que dão significado e sentido à organização.

Nessa mesma linha, pode-se dizer que se uma organização é uma relação de vínculos entre seus agentes - de suas representações, subjetividades e sentidos -, esses vínculos se legitimam, são acionados, estabelecidos e fortalecidos mediante a comunicação 
(BALDISSERA, 2014). Logo, “essas relações vinculativas compreendem processos comunicacionais em que os diversos sujeitos tensionados [...] transacionam significação, e com isso, (re)tecem permanentemente a própria organização" (BALDISSERA, 2014, p. 114).

Dessa forma, ao vincular o processo comunicativo ao conceito de competência de uma organização, percebemos que os agentes dessa organização são o centro dessa perspectiva, uma vez que são eles os dinamizadores e mobilizadores de competências individuais e coletivas que, em contato com o contexto vivido - particular, ambiental e situacional - projetaam uma rede de conhecimentos, de saberes múltiplos e práticas diversificas voltados para a inovação.

Segundo Fleury e Fleury (2000, p. 21), competência pode ser compreendida como "um saber agir responsável e reconhecido que implica mobilizar, integrar, transferir conhecimentos, recursos, habilidades, que agreguem valor econômico e valor social ao indivíduo".

Ao desenvolver uma competência, um indivíduo não apenas estaria mobilizando qualificações para realizar determinadas tarefas. Mais que isso, este indivíduo mobilizaria um conjunto de recursos cognitivos que, segundo Perrenoud (1999), seriam aplicados para solução de diversas situações. Logo, a competência pode estar relacionada ao estoque de recursos que o indivíduo detém (FLEURY; FLEURY, 2001). Esses recursos representam o acúmulo de significações, de aprendizados, de vivências, conhecimentos e relações em interação com contextos singulares, associados às experiências, modelos mentais e à própria personalidade e subjetividade do indivíduo. Criam o repertório afetivo, cognitivo e mental que leva o indivíduo ao enfrentamento de determinadas situações e, certamente, a reagir adequadamente diante delas (ALLESSANDRINI, 2002).

Para Perrenoud (1999, p.7), competência é "uma capacidade de agir eficazmente em um determinado tipo de situação, apoiada em conhecimentos, mas sem limitar-se a eles". Ao citarem Zarifian (1999), Fleury e Fleury (2001) corroboram com esta assertiva ao afirmarem que a competência é a inteligência prática de um indivíduo voltada para situações que se apoiam sobre os conhecimentos adquiridos e os transformam com tanto mais força quanto mais aumenta a complexidade das situações.

Ao relacionar competências individuais às competências essenciais de uma organização podemos presumir que haja a interseção entre o sujeito e a própria organização, no sentido de que este poderá lançar mão do "estoque de recursos" em prol do melhor desempenho da organização.

Sobre esta questão, Fleury e Fleury (2001, p. 187) observam que "do lado da organização, as competências devem agregar valor econômico para a organização e valor social para o indivíduo". Pressupõem, portanto, uma troca de valores, numa dinâmica 
sistêmica em que, ao passo em que a organização pode melhorar sua performance ao recorrer às competências de seus agentes, estes agregam valor social às suas vidas ao contribuir para que isso ocorra.

É papel da organização facilitar a transformação desses conhecimentos, recursos e habilidades em competências. Portanto, cabe à organização construir competências que sejam capazes de tornar-se seu core business ou competências essenciais. Melhor dizendo, "construir uma competência significa aprender a identificar e a encontrar os conhecimentos pertinentes para resolver uma situação-problema. É uma verdadeira rede de identificação, articulação e transmissão de conhecimentos” (SANTOS, 2006, p. 3).

Por competências essenciais entendemos as "competências e atividades mais elevadas, no nível corporativo, que são chave para a sobrevivência da empresa e centrais para sua estratégia" (ZACCARELLI, 2004 apud CAMPOS; GUIMARÃES, 2009, p.11).

Não obstante, como apontam Prahalad, Hamel e Rumelt (1994, xvi apud OLIVEIRA JR, 2008, p.127), as competências essenciais possuem certas características principais que a determinam e as colocam no centro da vantagem competitiva em uma organização:

- abrangência corporativa: competências essenciais fornecem a sustentação a vários produtos ou negócios dentro de uma corporação. Não são propriedade de uma área ou indivíduo isoladamente;

- estabilidade no tempo: produtos são a expressão momentânea das competências essenciais de uma corporação. Competências são mais estáveis e evoluem mais lentamente do que os produtos;

- aprendizagem ao fazer: competências são ganhas e aperfeiçoadas por meio do trabalho operacional e do esforço gerencial no dia a dia. Quanto mais se investe e desenvolve uma competência, maior sua distinção em relação aos competidores;

- locus competitivo: a competição de produto-mercado é meramente a expressão superficial de uma competição mais profunda em termos de competências. A competição atual se dá em torno de competências e não de produtos e serviços. (grifos do autor)

Oliveira Jr (2008) chama-nos atenção para o fato de que as mesmas competências essenciais que asseguram vantagem competitiva à organização em determinado contexto podem constituir-se em dificuldades em outros cenários. Portanto, as competências essenciais são consubstanciadas pelo contexto em que uma organização está inserida. Dessa forma, as competências essenciais não devem se tornar uma "rigidez essencial" a ponto de inibirem a 
inovação. Logo, as características principais apontadas por Prahalad, Hamel e Rumelt (1994 apud OLIVEIRA JR, 2008) devem tornar-se indicadores, inclusive de mudanças, uma vez que as organizações devem tornar as competências essenciais renováveis na medida em que o contexto exige certa flexibilidade em função da sua inconstância e vulnerabilidade.

Contextos instáveis e vulneráveis são comuns na contemporaneidade. Isso requer que as organizações criem e desenvolvam competências essenciais que reverberem em congruências com um ambiente de mudanças. Para Teece, Pisano e Schuen (1997, p. 515 apud OLIVEIRA JR, 2008), “certas respostas inovativas são necessárias quando o 'timing' do mercado é crítico, a taxa de mudança tecnológica é rápida e a natureza da futura competição e os mercados são de difícil determinação".

Nessa linha, acreditamos que gerar inovação por meio de competências essenciais torna-se um fator relevante para organizações inseridas em ambiente turbulentos e mutáveis.

Mas como mobilizar competências essenciais para a inovação? Acreditamos que uma organização, para se tornar inovativa, deverá desenvolver um modelo de gestão voltado para a cultura de inovação, alicerçado por processos comunicacionais que sejam capazes de integrar indivíduos e grupos.

Para Marx (2011, p. 21), a mobilização de indivíduos e grupos tem relação muito intensa com os processos de comunicação que se exercitam e se desenham no interior das organizações. Nessa mesma linha, Zarifian (2001 apud MARX, 2011, p. 21) observa que "as competências só são utilizadas e se desenvolvem como consequência de uma automobilização do indivíduo. [...] Isto coloca para as empresas o desafio de 'criar' condições, as mais favoráveis, para que os indivíduos "queiram mobilizar as suas competências"”.

Portanto, a forma como a comunicação se relaciona e colabora na constituição de uma organização compõe um forte elemento indutor do processo de inovação no âmbito organizacional. Trata-se do reconhecimento da comunicação como uma competência essencial, que pressupõe a hibridização da competência em comunicação da organização com a cultura de inovação. Dito de outro modo, a formação repertorial e comportamental gerada pela comunicação no cotidiano organizacional poderá refletir no processo de inovação organizacional.

Para Duarte e Monteiro (2009), a competência em comunicação é a transformação da comunicação em competência essencial da organização. Com ela, uma organização é capaz de empoderar os indivíduos como agentes autônomos de comunicação. Isso implica em torná-los protagonistas dos processos de comunicação, capazes de lidar com os desafios e problemas diários impostos pela rotina comunicativa e organizacional, desenvolvendo formas criativas de resolvê-los e ressignificando a realidade organizacional. 
Adicionalmente, a obtenção da competência em comunicação implica em tomadas de decisões ajustadas à mudança de mentalidade interna que valorize a comunicação como fator chave de desempenho corporativo. Isso significa pensar a comunicação complexa de modo que a dinâmica sociocultural, tecnológica e midiática dos processos simbólicos e constitutivos crie uma rede de significados e significantes que deem sentido aos arranjos organizacionais.

Aliada à promoção da cultura de inovação, a comunicação assumiria seu protagonismo no core business da organização, com posição estratégica privilegiada, uma vez que faria emergir significados compartilhados, gerando relacionamentos colaborativos em prol da inovação.

Certamente que existem indicadores que podem balizar o desenvolvimento de competência em comunicação no âmbito das organizações. Ao citar Hernández (2007), por exemplo, Bermúdez e Gonzáles $(2011$, p. 8) destacam a existência de quatro elementos-chave que definem a competência em comunicaçãonas organizações: 1) a capacidade de compreender e aceitar a visão do outro (legitimação de percepção); 2) a valorização adequada de si mesmo; 3 ) a busca por informação objetiva e requerida no processo comunicativo e 4) o autocontrole emocional.t

Nessa mesma linha, as autoras destacam algumas habilidades que podem ser agrupadas em três grandes categorias e que promoveriam a competência em comunicação nas organizações, como se apresenta no quadro 2 :

Quadro 2. Competências em comunicação necessárias no âmbito das organizações

\begin{tabular}{|c|c|c|}
\hline $\begin{array}{c}\text { Competências } \\
\text { linguísticas }\end{array}$ & Competências gerenciais & Competências relacionais \\
\hline Discursivas & Autocontrole & Capacidade de ouvir \\
\hline Psicolinguísticas & $\begin{array}{c}\text { Busca por informação objetiva para o } \\
\text { desenvolvimento do processo de comunicação }\end{array}$ & $\begin{array}{c}\text { Empatia e confiança } \\
\text { Capacidade de entender e aceitar } \\
\text { o ponto de vista de outra pessoa }\end{array}$ \\
\hline Sociolinguísticas & Tomada de decisão & Atitude comunicativa \\
\hline
\end{tabular}

Fonte: Bermúdez; Gonzalez (2011, p. 103-104) - tradução livre

Reforçamos a ideia sobre a complexidade que envolve o conceito de competência em comunicação, uma vez que refere-se a um estudo ainda incipiente e multidisciplinar. Quando relacionada às organizações, a competência em comunicação nos leva a compreender a intrincada rede de elementos que devem trazer resultados efetivos. Isso porque: 
Para obtener y afianzar estas competencias es necesario que el individuo cumpla con prerrequisitos tales como habilidades para realizar operaciones mentales, cognitivas, socioafectivas y psicomotoras específicas del ejercicio profesional. Pero su desarrollo dependerá de las características individuales requeridas para enfrentar un proceso de aprendizaje constante, en función de las exigencias de su cargo y de los objetivos de la organización (BERMÚDEZ; GONZALEZ, 2011, p. 104)

Logo, podemos inferir que a competência em comunicação voltada para a promoção e legitimação de uma cultura de inovação possui complexidade estratégica e é um processo que requer ambientes organizacionais de aprendizagem que valorizem a comunicação e favoreçam o desenvolvimento de significados compartilhados sobre inovação entre os agentes organizacionais envolvidos no processo de geração de inovação.

Esses arranjos organizacionais, agora voltados à cultura de inovação, são traduzidos pela cultura organizacional, uma vez que "[...] é a base fundamental para a geração contínua de inovações" (TERRA; RIJNBACH, s/d, p. 2).

Para um melhor entendimento, queremos dizer que a cultura de inovação deve ser incorporada ao modelo de gestão da organização e fazer parte daquilo que habitualmente no mundo empresarial se conceitua como "DNA" da empresa. Significa que a inovação deve ser parte estratégica da dinâmica organizacional que direciona atividades diversas, que instrui as ações e a missão empresarial, mas acima de tudo, constrói significado organizacional compartilhado, dinamizando as rotinas dos agentes participantes e os transformando em agentes inovativos. Para tanto, uma organização com disposição para inovar necessita incentivar a comunicação entre seus agentes para que tenham liberdade de expressão e passem a considerar a utilização criativa do conhecimento, por meio de sugestões, ideias e propostas de novos olhares sobre os processos organizacionais.

Prego (2014), ao refletir sobre como criar uma cultura de inovação que funcione, afirma que se enfrenta um grande desafio nesse sentido. Para ele, empresas que buscam alinhar padronização de processos e medição de resutados à inovação precisam criar ambientes que permitam a expressão do talento e da criatividade dos seus agentes. Tratase de superar modelos que prendem as organizações em padrões de comportamento e condutas estanques e colocar as pessoas da organização como promotores de inovação e interagentes.

O autor ainda afirma que a cultura de inovação possui quatro componentes básicos que, se bem aplicados, podem se converter em pilares para criar uma cultura organizacional voltada para a criatividade e inovação (PREGO, 2014), representados na figura 1. 

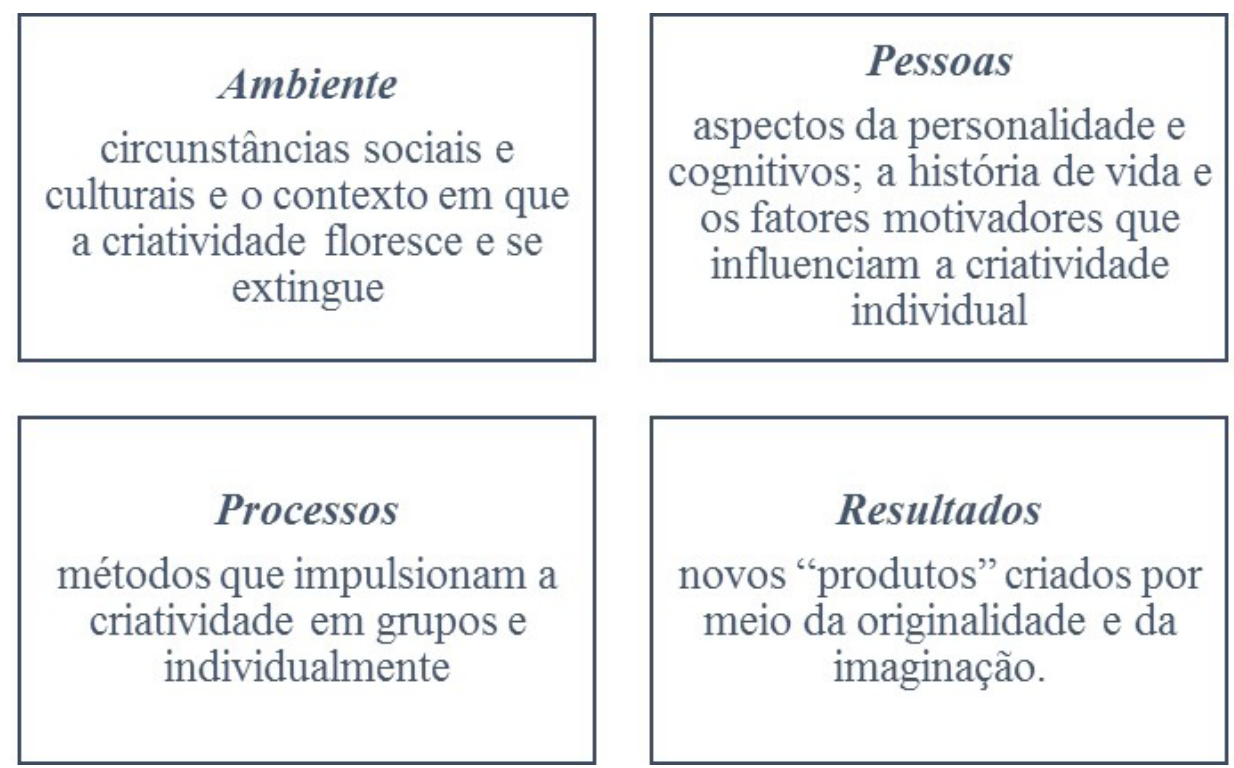

Figura 1. Componentes básicos para criar uma cultura de inovação

Fonte: adaptado de Rhodes (1961 apud PREGO, 2014, p.29) (tradução nossa)

Certamente que esses quatro componentes se sustentariam pela interação, na medida em que, aplicados de forma isolada, não poderiam gerar cultura de inovação. Isso passa a ser possível quando há comunicação sinérgica, capaz de dinamizar e integrar comportamentos e ações voltados para a aquisição de conhecimentos e a geração de inovação.

Ademais, conclui-se que organizações cuja comunicação esteja alinhada aos seus princípios e valores e seja considerada competência essencial e constituinte da mesma tenderiam a criar ambientes para o diálogo permanente, aberto e para o empoderamento de seus agentes, reforçando em cada ação comunicativa o seu interesse para a construção de uma cultura de inovação.

\section{Considerações finais}

Oferecendo uma visão dinâmica dos processos de interação e de relação entre os grupos, a competência em comunicação (core competence) é essencial num cenário organizacional que pretenda desenvolver habilidades que tornem seu modelo de gestão centrado em inovação. Sem competência em comunicação eficiente, ainda que a inovação possa orientar o processo de gestão nas organizações, não há como se manter num cenário em que decisões precisam ser tomadas a todo o momento. Torna-se evidente a importância da comunicação como oxigênio da organização, pois, por meio dela, a cultura de inovação e a gestão organizacional se sustentam e estimulam os processos existentes. 
Logo, o reconhecimento da inovação como modelo de gestão passa necessariamente pela incorporação da cultura organizacional que estimule a inovação, que pode estar ligada à criação de uma competência em comunicação por parte da organização.

A competência em comunicação está, portanto, diretamente relacionada à estrutura, à cultura e à gestão organizacional, que possibilitam a dinâmica necessária para a inovação como um todo.

Finalmente, podemos dizer que a incorporação de uma cultura de inovação por uma organização é uma tomada de consciência inovativa que redefine o modelo mental que rege esta organização. Isso requer mudança de padrões culturais da forma como ela se vê no mundo, o que quer para si, para seus agentes e outros públicos que interagem com ela - que são influenciados por suas ações e as influenciam reciprocamente.

Ao incorporar uma cultura voltada para inovação, a organização deverá empenhar-se para seu êxito. Medir resultados, estimular novas práticas e reconhecer esforços estão entre os caminhos que devem ser adotados para que a cultura de inovação funcione.

Prego (2014) é categórico ao afirmar que "lo realmente importante es si esa propuesta está alineada con la 'hoja de ruta' y con aquellos aspectos en los que la organización necesita ahora centrar sus esfuerzos innovadores".

Contribui ainda ao apresentar passos e/ou processos para criar uma cultura de inovação que funcione, quais sejam:

Criar uma visão inspiradora: desenhar/imaginar um futuro o qual todos desejam e no qual trabalhem juntos para construi-lo;

Envolver a todos: eliminar a visão endógena da geração de inovação e de ideias;

Esclarecer os comportamentos do líder: definir claramente os novos papéis e responsabilidades de cada líder;

Criar tempo e espaço para explorar: a criatividade não ocorre no "vazio" e não deveria ser uma atividade para "o tempo livre ou ocioso";

Estimular a responsabilidade pessoal: deixar de entender a criatividade como um "hobby" e inclui-la na lista de tarefas como qualquer outra;

Desenvolver a habilidade para criar e inovar: oferecer ao talento as ferramentas que permitam expressar todo o seu potencial;

Medir a inovação: estabelecer métricas (instrumentos de medição/avaliação) realistas e úteis para acompanhar o progresso e a evolução dos esforços de inovação;

Aproveitar as novas tecnologias: substituir a "caixa de ideias" e os "concursos de inovação" por ferramentas mais sofisticadas e rentáveis;

Criar uma rede de facilitadores: contar com uma rede de apoio para as iniciativas inovadoras dentro da organização; 
Fomentar/estimular as conexões: eliminar compartimentos estancos/isolados e contribuir para a "polinização cruzada" entre áreas e departamentos;

Atribuir orçamentos e recursos: de acordo com as prioridades da nossa empresa, evitando os "comitês" e o investimento clássico de I+D+I (Pesquisa + Desenvolvimento + Inovação), selecionando novas fórmulas de atribuição de orçamentos e recursos;

Criar um clima livre de medo: o medo é, em relação à criatividade, o que a kriptonita é em relação ao Superman. Uma organização com medo nunca terá superpoderes criativos. (PREGO, 2014, p. 33) (tradução nossa).

Sem querer esgotar o assunto, permitimo-nos defender que a comunicação é o elo que integra esses processos. Ao entendermos que a inovação em uma organização é um processo contínuo, a comunicação deve ser uma competência essencial para legimá-lo.

\section{Referências}

AHMED, P. Culture and climate for innovation. European Journal of Innovation Management, v. 1, n. 1, p. 30-43, 1998.

ALLESSANDRINI, C.D. O desenvolvimento de competências e a participação pessoal na construção de um novo modelo educacional. In: PERRENOUD, P. et al. As competências para ensino no século XXI: a formação dos professores e o desafio da avaliação. Porto Alegre: Artmed Editora, 2002. p. 157-176.

BALDISSERA, R. A complexidade dos processos comunicacionais e a interação nas organizações. In: MARCHIORI, M. (org.). Cultura e interação. São Caetano do Sul, SP: Difusão Editora; Rio de Janeiro: Editora Senac, 2014. p. 113-124.

BERGER, P.L; LUCKAMNN, T. A construção social da realidade: tratado sobre sociologia do conhecimento. 23 ed. Petrópolis, RJ: Vozes, 2003.

BERMÚDEZ, L; GONZÁLEZ, L. La competência comunicativa: elemento clave em las organizaciones. Redalyc.org, v. 8, n. 15, enero./jun., p. 95-110, 2011. Disponível em: <http://www.redalyc.org/ articulo.oa?id=199018964006>. Acesso em: 03 mar. 2015.

BRUNO-FARIA, M.F; FONSECA, M. Cultura de Inovação: conceitos e modelos teóricos. Revista de Administração Contemporânea, Curitiba, v. 18, n. 4, jul./ago. 2014. Disponível em: <http://www. scielo.br/scielo.php?pid=S1415-65552014000400372\&script=sci_arttext $>$. Acesso em: 19 jul.

CALDAS, M. O nexo comunicação-organização: um prelúdio às múltiplas avenidas de cooperação e de mútuo aprendizado entre comunicação organizacional e estudos organizacionais. In: MARCHIORI, M. (org.). Comunicação e organização: reflexões, processos e práticas. São Caetano do Sul, SP: Difusão Editora, 2010. p. 29-46. 
CAMPOS, J.; GUIMARÃES, S. Em busca da eficácia em treinamento. São Paulo: Associação Brasileira de Treinamento e Desenvolvimento, 2009.

CASTELLS, M. A sociedade em rede. São Paulo: Paz e Terra. v. 1, 1999.

CHESBROUGH, H. Open innovation: the new imperative for creating and profiting from technology. Boston: Harvard Business School Press, 2006.

DOBNI, C. Measuring innovation culture in organizations: the development of a generalized innovation culture construct using exploratory factor analysis. European Journal of Innovation Management, 11(4), 539-559. doi: 10.1108/14601060810911156, 2008. Disponível em: < http://www.emeraldinsight.com/doi/pdfplus/10.1108/14601060810911156>. Acesso em: 23 mar. 2015.

DMITRUK, H.B. Pesquisa bibliográfica e outros tipos de pesquisa. In: . (org.) Cadernos metodológicos: diretrizes do trabalho científico. 6 ed. Chapecó: Argos, 2004. p. 67-76.

DUARTE, J; MONTEIRO, G. Potencializando a comunicação nas organizações. In. KUNSCH, M. (org.). Comunicação organizacional: linguagem, gestão e perspectivas, volume 2. São Paulo: Saraiva, 2009. p. 333-359.

FLEURY, A.C.C; FLEURY, M.T.L. Estratégias empresariais e formação de competência. São Paulo: Atlas, 2000.

. Construindo o conceito de competência. RAC, Curitiba, Edição Especial, v. 5, p. 183-196. Disponível em: <http://www.scielo.br/pdf/rac/v5nspe/v5nspea10.pdf $>$. Acesso em: 15 mar. 2015.

FREEMAN, C. The economics of industrial innovation. 2 ed. London: Frances Pinter, 1982.

JASKYTE, K; DRESSLER, W. Studying culture as an integral aggregate variable: organizational culture and innovation in a group of nonprofit organizations. Field Methods, 16(3), 265-284. 2004. doi: 10.1177/1525822X03262281. Disponível em: <http://fmx.sagepub.com/content/16/3/265>. Acesso em: 20 abr. 2015.

JEKINS, H. Cultura da Convergência. 2 ed. São Paulo: Aleph, 2009.

KAASA, A; VADI, M. How does culture contribute to innovation? Evidence from European countries. Economics of Innovation and New Technology, 19(7), 2010. Disponível em: <http://www.mtk. ut.ee/sites/default/files/mtk/RePEc/mtk/febpdf/febawb63.pdf>. Acesso em: 20 mar. 2015.

KNOX, S. The boardroom agenda: developing the innovative organization. Corporate Governance, 2(1), 27-36. 2002. Disponível em: <http://dx.doi.org/10.1108/14720700210418698>. Acesso em: 10 fev. 2015.

LEVY, P. Cibercultura. São Paulo: Editora 34, 1999.

MARCHIORI, M. Cultura e comunicação organizacional: um olhar estratégico sobre a organização. 2 ed. São Caetano, SP: Difusão Editora, 2008.

MARX, O. Organização do trabalho para inovação: uma avaliação crítica dos projetos e da implantação de trabalho em grupos com autonomia. São Paulo: Atlas, 2011.

$110 \frac{\text { Comunicação \& Inovação, PPGCOM/USCS }}{\text { v. 17, n. 33 (95-111) jan-abr } 2016}$ 
MOURA, H.; KRUMHOLZ, I. A criação de uma cultura de inovação em empresas de Tecnologia da Informação apoiada pelos métodos do Design Estratégico. 2010. Disponível em: <http://blogs. anhembi.br/congressodesign/anais/artigos/69523.pdf>. Acesso em: 02 mar. 2015.

OCDE. Manual de Oslo: diretrizes para coleta e interpretação de dados sobre inovação. 2005. Disponível em: <http://www.mct.gov.br/upd_blob/0026/26032.pdf>. Acesso em: 03 mar. 2015.

OLIVEIRA JR, M. Competências essenciais e conhecimento na empresa. In: FLEURY; M.; OLIVEIRA JR, M. (orgs.). Gestão estratégica do conhecimento: integrando aprendizagem, conhecimento e competências. São Paulo: Atlas, 2008. p. 121-156.

PERRENOUD, P. Construir as competências desde a escola. Tradução de Bruno Charles Magne. Porto Alegre: Artes Médicas Sul, 1999.

PREGO, J. Cómo crear una cultura de innovación que funcione. 2014. Disponível em: <https://zmx.bauru. unesp.br/service/home/ /?auth=co\&loc=pt_BR\&id=48888\&part=2.>. Acesso em: 18 jul. 2015.

SANTOS, B.B.M. Apropriação do conceito de competência na prática social. ANPUH. 2006. Disponível em: $<\mathrm{http} / /$ www.rj.anpuh.org/resources/rj/Anais/2006/conferencias/Beatriz\%20Boclin\%20Marques\%20 dos\%20Santos.pdf $>$. Acesso em: 10 mar. 2015.

SCHUMPETER, J. Teoria do desenvolvimento econômico. São Paulo: Abril Cultural, 1982.

STEELE, J; MURRAY, M. Creating, supporting and sustaining a culture of innovation. Engineeering, Construction and Architectural Management, 11(5), 316-322. doi: 10.1108/09699980410558502, 2004. Disponível em: < http://www.emeraldinsight.com/doi/abs/10.1108/09699980410558502>. Acesso em: 20 mar. 2015.

STEVENS, T. Gerenciamento das idéias. HSM Management. São Paulo, n. 6, p. 70-73, jan./fev., 1998.

TERRA, J.C.C; RIJNBACH, C.B.V. Cultura de inovação. Fórum Terra. (s/d). Disponível em: <http:// biblioteca.terraforum.com.br/BibliotecaArtigo/CulturadeInovacao.pdf>. Acesso em: 2 mar. 2015.

TIDD, J; BESSANT, J; PAVITT, K. Gestão da inovação. Porto Alegre: Bookman, 2008.

ZMOGINSK, A. et al. Co-criação de valor: inovação no modelo de negócio obtendo vantagem competitiva. 2009. Disponível em: <http://www.mackenzie.br/dhtm/seer/index.php/jovenspesquisadores/ article/view/800>. Acesso em: 30 fev. 2015. 